Article

\title{
Structural Effects of Magnetostrictive Materials on the Magnetoelectric Response of Particulate CZFO/NKNLS Composites
}

\author{
Moon Hyeok Choi, Kyujin Ko and Su Chul Yang * (D) \\ Department of Chemical Engineering, Dong-A University, Busan 49315, Korea; ansur14927@gmail.com (M.H.C.); \\ rbwls0096@gmail.com (K.K.) \\ * Correspondence: scyang@dau.ac.kr
}

Received: 12 February 2019; Accepted: 28 March 2019; Published: 30 March 2019

check for updates

\begin{abstract}
In this study, magnetostrictive powders of $\mathrm{CoFe}_{2} \mathrm{O}_{4}(\mathrm{CFO})$ and $\mathrm{Zn}$-substituted $\mathrm{CoFe}_{2} \mathrm{O}_{4}$ $(\mathrm{CZFO}, \mathrm{Zn}=0.1,0.2)$ were synthesized in order to decrease the optimal dc magnetic field $\left(H_{\text {opt. }}\right)$, which is required to obtain a reliable magnetoelectric (ME) voltage in a 3-0 type particulate composite system. The CFO powders were prepared as a reference via a typical solid solution process. In particular, two types of heterogeneous CZFO powders were prepared via a stepwise solid solution process. Porous-CFO and dense-CFO powders were synthesized by calcination in a box furnace without and with pelletizing, respectively. Then, heterogeneous structures of $\mathrm{pCZFO}$ and $\mathrm{dCZFO}$ powders were prepared by Zn-substitution on calcined powders of porous-CFO and dense-CFO, respectively. Compared to the CFO powders, the heterogeneous pCZFO and dCZFO powders exhibited maximal magnetic susceptibilities $\left(\chi_{\max }\right)$ at lower $H_{\mathrm{dc}}$ values below \pm 50 Oe and \pm 10 Oe, respectively. The $Z n$ substitution effect on the $H_{\mathrm{dc}}$ shift was more dominant in dCZFO than in pCZFO. This might be because the $\mathrm{Zn}$ ion could not diffuse into the dense-CFO powder, resulting in a more heterogeneous structure inducing an effective exchange-spring effect. As a result, ME composites consisting of $0.948 \mathrm{Na}_{0.5} \mathrm{~K}_{0.5} \mathrm{NbO}_{3}-0.052 \mathrm{LiSbO}_{3}$ (NKNLS) with CFO, pCZFO, and dCZFO were found to exhibit $H_{\text {opt. }}=966$ Oe (NKNLS-CFO), $H_{\text {opt. }}=689-828$ Oe $\left(\right.$ NKNLS-pCZFO), and $H_{\text {opt. }}=458-481$ Oe (NKNLS-dCZFO), respectively. The low values of $H_{\text {opt. }}$ below 500 Oe indicate that the structure of magnetostrictive materials should be considered in order to obtain a minimal $H_{\text {opt. }}$ for high feasibility of ME composites.
\end{abstract}

Keywords: structural effect; magnetostrictive powders; hysteretic magnetization; magnetoelectric voltage; optimal dc magnetic field; particulate composites; CZFO; NKNLS

\section{Introduction}

Since the year 2000, magnetoelectric (ME) response has been a topic of interest in the development of energy-harvesters, sensitive magnetic sensors, and magnetically driven memories, or magnetoelectric transducers [1-3]. The ME effect is a result of induced piezoelectric effect (electrical effect/mechanical) in a piezoelectric phase by strain transfer of the magnetostrictive effect (mechanical/magnetic) in a magnetostrictive phase [4-8].

$$
\text { ME effect }=\frac{\text { electric }}{\text { mechanical }} \times \frac{\text { mechanical }}{\text { magnetic }}
$$

However, reliable ME voltage from 3-0 type particulate composites can only be obtained under an optimal dc magnetic field $\left(H_{\text {opt. }}\right)$ on the order of over several thousand Oersteds (Oe), which is a serious drawback limiting practical ME applications $[9,10]$. According to previous studies on particulate 
ME composites, a maximum ME voltage $\left(\alpha_{\mathrm{ME}}\right)$ was obtained at high values of $H_{\mathrm{opt}}$ above 1000 Oe from various compositions of $\mathrm{Pb}\left(\mathrm{Zr}_{0.52} \mathrm{Ti}_{0.48}\right) \mathrm{O}_{3}-\mathrm{Ni}_{0.8} \mathrm{Zn}_{0.2} \mathrm{Fe}_{2} \mathrm{O}_{4}\left(\alpha_{\mathrm{ME}}=54.4 \mathrm{mV} / \mathrm{cm} \cdot\right.$ Oe at $H_{\text {opt. }}=1000$ Oe), $\mathrm{BaTiO}_{3}-\mathrm{Co}_{0.6} \mathrm{Zn}_{0.4} \mathrm{Fe}_{1.7} \mathrm{Mn}_{0.3} \mathrm{O}_{4}\left(\alpha_{\mathrm{ME}}=73 \mathrm{mV} / \mathrm{cm} \cdot \mathrm{Oe}\right.$ at $\left.H_{\text {opt. }}>2000 \mathrm{Oe}\right), \mathrm{BaTiO}_{3}-\mathrm{CoFe}_{2} \mathrm{O}_{4}$ $\left(\alpha_{\mathrm{ME}}=17.04 \mathrm{mV} / \mathrm{cm} \cdot \mathrm{Oe}\right.$ at $\left.H_{\text {opt. }}>15,000 \mathrm{Oe}\right), \mathrm{Ba}_{0.85} \mathrm{Ca}_{0.15} \mathrm{Ti}_{0.9} \mathrm{Zr}_{0.1} \mathrm{O}_{3}-\mathrm{CoFe}_{2} \mathrm{O}_{4}\left(\alpha_{\mathrm{ME}}=1.028 \mathrm{mV} / \mathrm{cm} \cdot \mathrm{Oe}\right.$ at $\left.H_{\text {opt. }}>8000 \mathrm{Oe}\right)$, and $\mathrm{Na}_{0.5} \mathrm{Bi}_{0.5} \mathrm{TiO}_{3}-\mathrm{CoFe}_{2} \mathrm{O}_{4}\left(\alpha_{\mathrm{ME}}=0.42 \mathrm{mV} / \mathrm{cm} \cdot\right.$ Oe at $\left.H_{\text {opt. }}>2500 \mathrm{Oe}\right)$ [11-15].

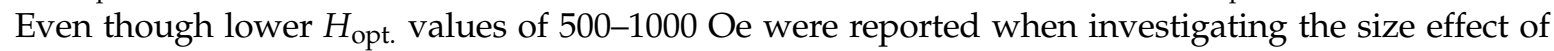
magnetostrictive particles in $\mathrm{BaTiO}_{3}-\mathrm{NiFe}_{1.98} \mathrm{O}_{4}\left(\alpha_{\mathrm{ME}}=\sim 252 \mathrm{mV} / \mathrm{cm} \cdot\right.$ Oe at $\left.H_{\text {opt. }}=500-1000 \mathrm{Oe}\right)$, the sintering temperature effect in $\mathrm{Pb}\left(\mathrm{Zr}_{0.52} \mathrm{Ti}_{0.48}\right) \mathrm{O}_{3}-\mathrm{NiCo}_{0.02} \mathrm{Cu}_{0.02} \mathrm{Mn}_{0.1} \mathrm{Fe}_{1.8} \mathrm{O}_{4}\left(\alpha_{\mathrm{ME}}=63 \mathrm{mV} / \mathrm{cm} \cdot \mathrm{Oe}\right.$ at $\left.H_{\text {opt. }}=600 \mathrm{Oe}\right)$, and the piezoelectric phase effect in $\mathrm{Pb}\left(\mathrm{Zr}_{0.52} \mathrm{Ti}_{0.48}\right) \mathrm{O}_{3}-\mathrm{Ni}_{1-x} \mathrm{Zn}_{x} \mathrm{Fe}_{2} \mathrm{O}_{4}$ $\left(\alpha_{\mathrm{ME}}=190 \mathrm{mV} / \mathrm{cm} \cdot\right.$ Oe at $\left.H_{\text {opt. }}=800 \mathrm{Oe}\right)$, there is still a need to decrease $H_{\text {opt. }}$ below 100 Oe for a high feasibility of particulate ME composite [16-18].

In this study, the structural effects of magnetostrictive materials on ME response was investigated

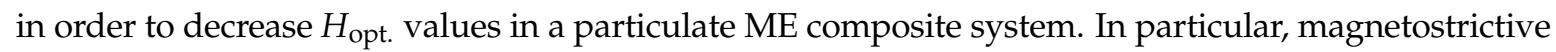
powders of $\mathrm{CoFe}_{2} \mathrm{O}_{4}$ (CFO), Zn-substituted porous-CFO (pCZFO) and Zn-substituted dense-CFO (dCZFO) were respectively prepared to explore structure-dependent hysteretic magnetizations. Then the $H_{\text {opt. }}$ shift in $\mathrm{ME}$ response was analyzed in particulate $\mathrm{ME}$ composites consisting of each magnetostrictive powder (CFO, pCZFO, and dCZFO) in a $0.948 \mathrm{Na}_{0.5} \mathrm{~K}_{0.5} \mathrm{NbO}_{3}-0.052 \mathrm{LiSbO}_{3}(\mathrm{NKNLS})$ piezoelectric matrix.

\section{Experimental}

Figure 1a-c shows a schematic diagram of the experimental procedure based on a solid-solution method to synthesize magnetostrictive powders of CFO, pCZFO, and dCZFO, respectively. As shown in Figure 1a, for preparation of $\mathrm{CFO}$ powders, $\mathrm{Co}_{3} \mathrm{O}_{4}$ (Sigma-Aldrich, Seoul, Korea, $\geq 99.5 \%$ ) and $\mathrm{Fe}_{2} \mathrm{O}_{3}$ (Sigma-Aldrich, Seoul, Korea, $\geq 99.0 \%$ ) powders were mixed by ball milling for $24 \mathrm{~h}$. The well-mixed and fully dried powders were calcined at $1000{ }^{\circ} \mathrm{C}$ for $2 \mathrm{~h}$. The calcined powders were ball-milled for $24 \mathrm{~h}$ and then sintered at $1200{ }^{\circ} \mathrm{C}$ for $2 \mathrm{~h}$. After crushing and sieving of the sintered powders, CFO powders were selected with a particle size of $24-64 \mu \mathrm{m}$. As shown in Figure 1b,c, for preparation of pCZFO and dCZFO powders, $\mathrm{Co}_{3} \mathrm{O}_{4}$ (Sigma-Aldrich, Seoul, Korea, $\geq 99.5 \%$ ) and $\mathrm{Fe}_{2} \mathrm{O}_{3}$ (Sigma-Aldrich, Seoul, Korea, $\geq 99.0 \%$ ) powders were mixed by ball milling for $24 \mathrm{~h}$. Then, the well-mixed and fully dried powders were calcined at $1000{ }^{\circ} \mathrm{C}$ for $2 \mathrm{~h}$ without and with pelletizing at 30 bar pressure, respectively. The calcined CFO powders exhibiting a porous structure (pCFO) and a dense structure (dCFO) were mixed with 0.1 and 0.2 molar ratio of $\mathrm{ZnO}$ powders (Sigma-Aldrich, Seoul, Korea, $\geq 99.0 \%$ ), respectively. Then the mixed powders were sintered at $1200{ }^{\circ} \mathrm{C}$ for $2 \mathrm{~h}$. After crushing and sieving of the sintered powders, $\mathrm{pCZFO}$ and dCZFO powders were selected with particle sizes of $24-64 \mu \mathrm{m}$.

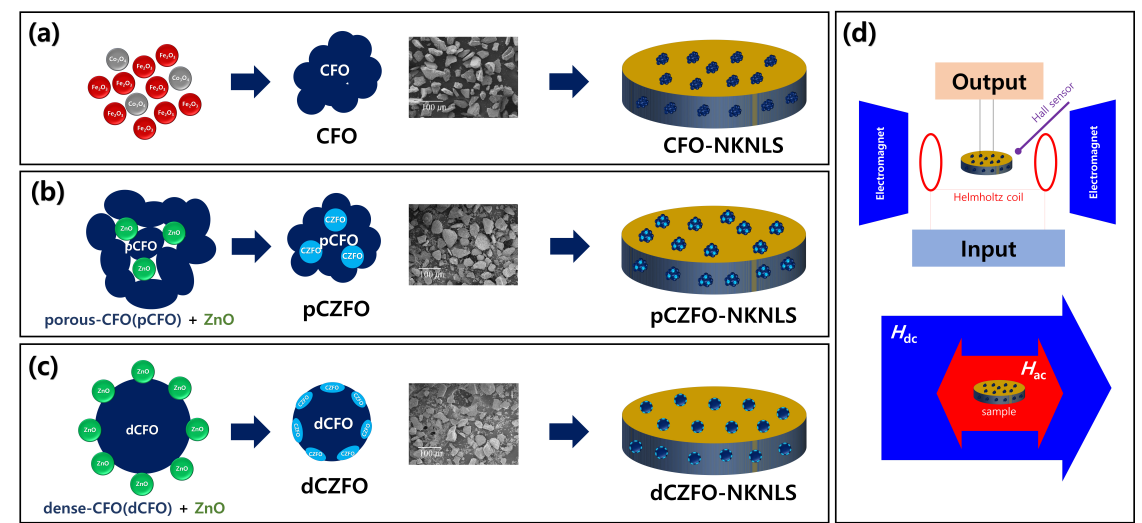

Figure 1. Schematic diagram of experimental procedure based on solid-solution synthesis for (a) $\mathrm{CoFe}_{2} \mathrm{O}_{4}$ (CFO), (b) Zn-substituted porous-CoFe $\mathrm{O}_{4}$ (pCZFO), and (c) Zn-substituted dense- $\mathrm{CoFe}_{2} \mathrm{O}_{4}$ (dCZFO) powders. (d) Schematic diagram of magnetoelectric measurement set up. 
ME composites were prepared with a 3-0 type particulate structure consisting of the magnetostrictive powders (CFO, pCZFO, and dCZFO, respectively) in a lead-free piezoelectric matrix of NKNLS. For preparation of NKNLS powders, $\mathrm{K}_{2} \mathrm{CO}_{3}$ (Sigma-Aldrich, Seoul, Korea, $99 \%$ ), $\mathrm{Na}_{2} \mathrm{CO}_{3}$ (Sigma-Aldrich, Seoul, Korea, 99.5\%), $\mathrm{Li}_{2} \mathrm{CO}_{3}$ (Sigma-Aldrich, Seoul, Korea, 99\%), $\mathrm{Nb}_{2} \mathrm{O}_{5}$ (Sigma-Aldrich, Seoul, Korea, 99.9\%), and $\mathrm{Sb}_{2} \mathrm{O}_{5}$ (Sigma-Aldrich, Seoul, Korea, 99\%) powders were mixed by ball milling for $24 \mathrm{~h}$. Then, the well-mixed and fully dried powders were calcined at $880^{\circ} \mathrm{C}$ for $2 \mathrm{~h}$. After sintering at $1050^{\circ} \mathrm{C}$ for $2 \mathrm{~h}$ of CFO-NKNLS, pCZFO-NKNLS, and dCZFO-NKNLS pellets with a magnetostrictive/piezoelectric weight ratio of 0.1, disk-type ME composites were prepared with a thickness of $1 \mathrm{~mm}$ and a diameter of $13 \mathrm{~mm}$. The ME composites were poled in silicone oil at room temperature by applying a dc field of $3 \mathrm{kV} / \mathrm{mm}$ for $30 \mathrm{~min}$.

Crystal structures were investigated by X-ray diffraction (XRD; Miniflex600, RIGAKU, Tokyo, Japan) with $\mathrm{CuK}_{\alpha}(\lambda=1.5406 \AA)$ radiation. The surface morphology was investigated by scanning electron microscopy (SEM; JEOL-6700F, Tokyo, Japan). Hysteretic magnetization curves were characterized by vibrating sample magnetometry (VSM; Model 7404, Lakeshore, CA, USA). Piezoelectric constants were measured by an APC YE 2730A d33 meter (APC Inc., Mackeyville, PA, USA). ME voltages were measured by applying an $H_{\mathrm{ac}}$ of 1 Oe at an off-resonance frequency, $f$, of $1 \mathrm{kHz}$ using a lock-in amplifier (SR860, Stanford Research Systems Inc., Sunnyvale, CA, USA) [19,20]. As shown in Figure 1d, using the lock-in amplifier a calculated ac current was applied to a Helmholtz coil to induce an $H_{\mathrm{ac}}$ of 1 Oe with an off-resonance frequency of $1 \mathrm{kHz}$. Then, an $H_{\mathrm{dc}}$ of \pm 1000 Oe was applied to the ME samples using an electromagnet to obtain reliable ME voltages. Output ac voltage $\left(V_{\mathrm{ac}}\right)$ from the ME samples was measured by the lock-in amplifier.

\section{Results and Discussion}

Crystal structures of the magnetostrictive CFO, pCZFO ( $\mathrm{Zn}=0.1, \mathrm{Zn}=0.2)$, and dCZFO $(\mathrm{Zn}=0.1$, $\mathrm{Zn}=0.2)$ powders were investigated from XRD patterns. As shown in Figure 2a, all magnetostrictive powders were found to exhibit XRD peaks of (220), (311), (222), (400), (422), (511), and (440) representing a spinel structure of $\mathrm{AB}_{2} \mathrm{O}_{4}$ (JCPDS card No. 22-1086) [21,22]. Even though no noticeable peak shift in the XRD patterns was observed over a wide $2 \theta$ range after $\mathrm{Zn}$ substitution of 0.1 and 0.2 molar ratio on the porous-CFO and dense-CFO powders, a major shift of the (311) peak at $2 \theta=35.5^{\circ}$ towards a lower angle by $\mathrm{Zn}$ substitution was observed in the XRD patterns at a narrow $2 \theta$ range, as shown in Figure $2 \mathrm{~b}$. Bragg's Law can be used to calculate a lattice constant using the equation:

$$
a^{2}=\lambda^{2}\left(h^{2}+k^{2}+l^{2}\right)^{1 / 2} / 4 \sin ^{2} \theta
$$

where $\mathrm{a}$ is the lattice constant, $\lambda$ is the wavelength of $\mathrm{CuK}_{\alpha}$ radiation, and $\mathrm{h}, \mathrm{k}$, and $\mathrm{l}$ are the Miller indices. As the (311) peak shifts to a lower angle by $\mathrm{Zn}$ substitution, the lattice constant increases due to a decrease in the value of $\sin \theta$. With respect to the ionic radius, the $\mathrm{PCZFO}$ and dCZFO powders were found to exhibit an increased lattice constant compared to CFO powders because $\mathrm{Zn}^{2+}(0.82 \AA)$ has a larger ionic radius than $\mathrm{Co}^{2+}(0.78 \AA)$, which is replaced by $\mathrm{Zn}^{2+}[23-25]$. 
(a)

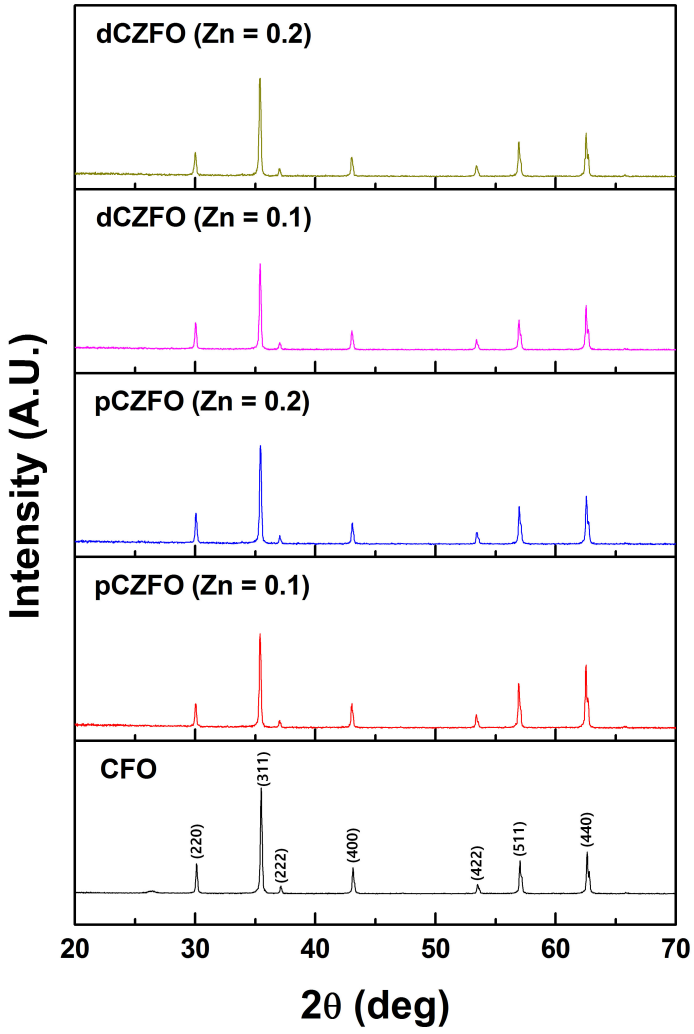

(b)

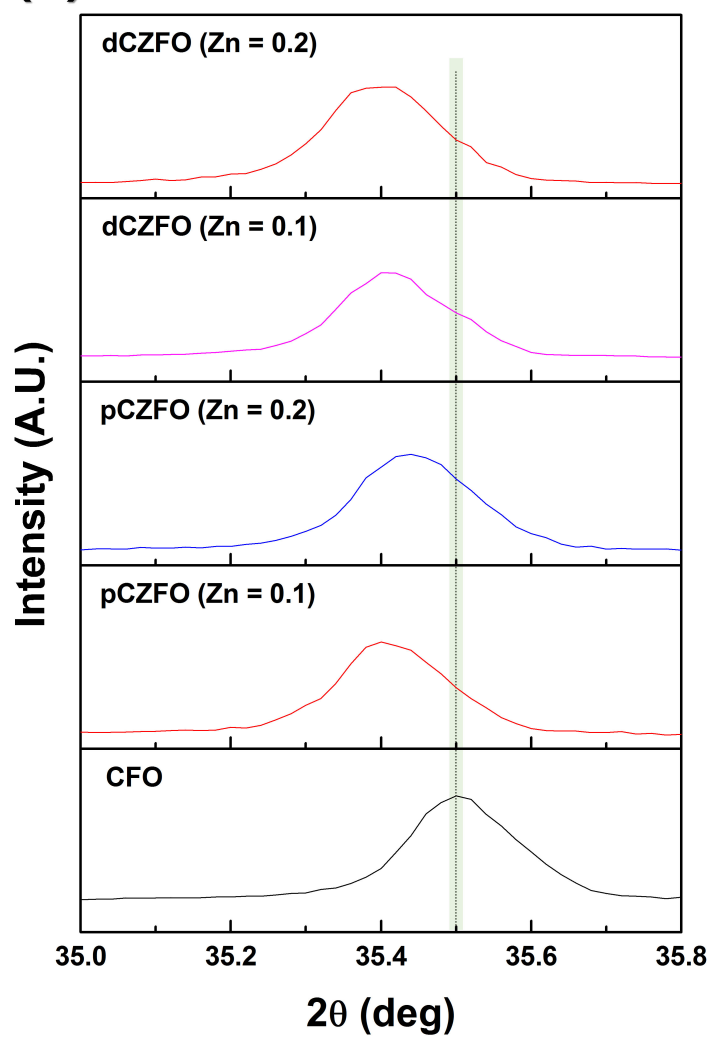

Figure 2. XRD patterns of CFO, pCZFO $(\mathrm{Zn}=0.1,0.2)$ and $\mathrm{dCZFO}(\mathrm{Zn}=0.1,0.2)$ powders; (a) wide range $2 \theta$ of $20-70^{\circ}$ and (b) narrow range $2 \theta$ of $35.0-35.8^{\circ}$.

In terms of $\mathrm{Zn}$ substitution in the porous-CFO and dense-CFO powders, magnetic properties of saturation magnetization $\left(M_{\mathrm{s}}\right)$, remanent magnetization $\left(M_{\mathrm{r}}\right)$, coercive field $\left(H_{\mathrm{c}}\right)$, and magnetic susceptibility $(\chi=\mathrm{d} M / \mathrm{d} H)$ were investigated, as shown in Figure 3 and Table 1 . Compared to the CFO powders, the $\mathrm{pCZFO}$ and $\mathrm{dCZFO}$ powders were found to exhibit enhanced $M_{\mathrm{S}}$ with decreased $H_{\mathrm{c}}$, as shown in Table 1 . The enhanced values of $M_{\mathrm{s}}$ demonstrate that the addition of $\mathrm{Zn}^{2+}$ ions causes a migration of $\mathrm{Fe}^{3+}$ ions from a tetrahedral site to an octahedral site, which causes an increase of the total magnetic moment by reducing the net magnetic moment in the tetrahedral site. Furthermore, decreased values of $H_{\mathrm{c}}$ illustrate that grain growth by $\mathrm{Zn}$ substitution causes an increase of the domain wall number, resulting in large grain size, which requires less energy for spin rotation [26,27]. As shown in Figure 3b,e, stepped demagnetization behavior is shown by $\mathrm{pCZFO}$ with $\mathrm{Zn}=0.2$ and dCZFO with $\mathrm{Zn}=0.1$ and 0.2 , which might be caused by the exchange-spring effect derived from the interplay of two uniquely characteristic phases [28-30]. From the result, it is noted that dCZFO possesses a sufficient exchange-spring effect based on high interaction between two magnetostrictive phases even though the $\mathrm{Zn}$ substitution of 0.1 is low in the dense-CFO powders. As shown in Figure 3c,f, the pCZFO and dCZFO powders were found to exhibit higher $\chi_{\max }$ of $0.22-0.42 \mathrm{emu} / \mathrm{g}$. Oe at lower values of $H_{\mathrm{dc}}$ below $\pm 50 \mathrm{Oe}$, compared to $\chi_{\max }$ of $0.05 \mathrm{emu} / \mathrm{g}$. Oe at an $H_{\mathrm{dc}}$ below \pm 200 Oe from the CFO powders. In particular, the $\chi_{\max }$ values of dCZFO were obtained at very low values of $H_{\mathrm{dc}}$ below \pm 10 Oe, which are induced by prominent stepped demagnetization behavior. 

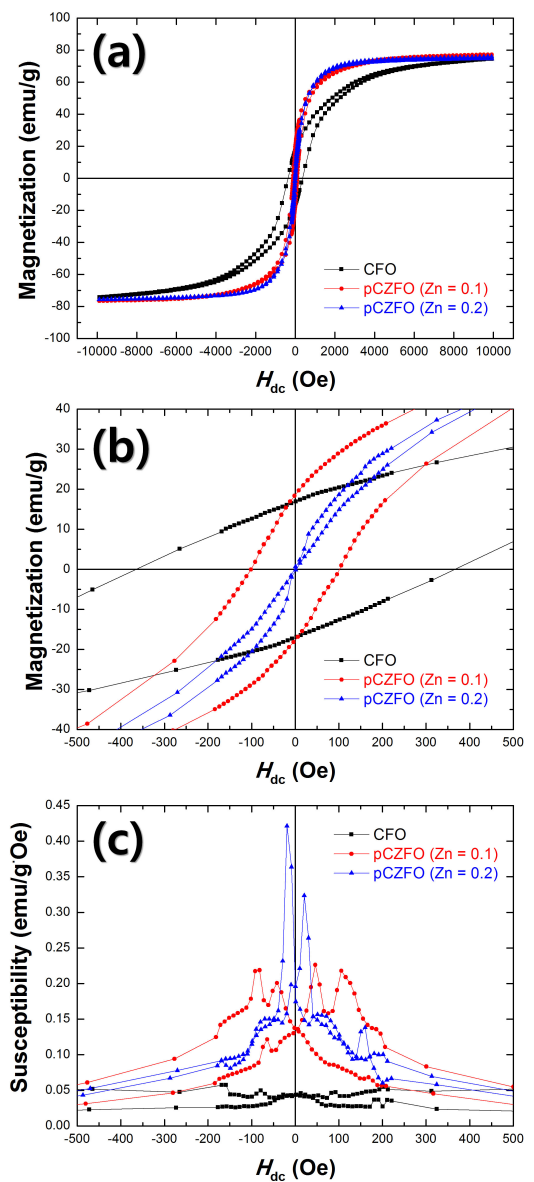
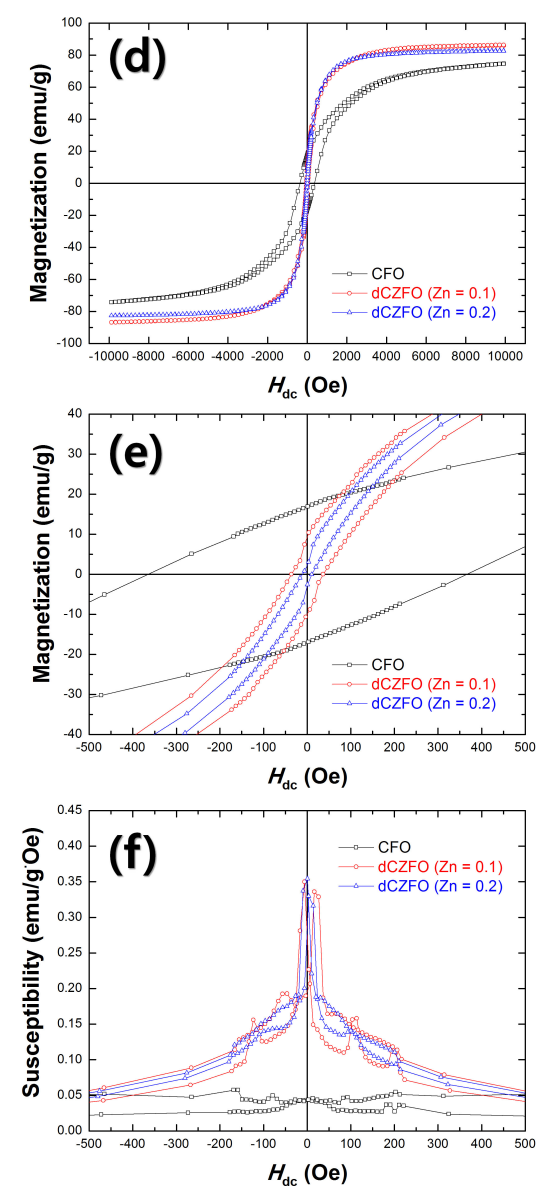

Figure 3. Hysteretic magnetization curves at (a,d) a wide $H_{\mathrm{dc}}$ range of $\pm 10 \mathrm{kOe}$ and $(\mathbf{b}, \mathbf{e})$ a narrow $H_{\mathrm{dc}}$ range of $\pm 1 \mathrm{kOe}$, (c,f) magnetic susceptibilities $(\chi)$ of CFO, pCZFO $(\mathrm{Zn}=0.1,0.2)$ and dCZFO $(\mathrm{Zn}=0.1$, $0.2)$ powders.

Table 1. Magnetic properties of $\mathrm{CoFe}_{2} \mathrm{O}_{4}$ (CFO), Zn-substituted porous-CoFe $\mathrm{O}_{4}$ (pCZFO) and $\mathrm{Zn}$-substituted dense-CoFe $\mathrm{O}_{4}$ (dCZFO) powders; saturation magnetization $\left(M_{\mathrm{s}}\right)$, remanent magnetization $\left(M_{\mathrm{r}}\right)$, coercive field $\left(H_{\mathrm{c}}\right)$, and magnetic susceptibility $(\chi=\mathrm{d} M / \mathrm{d} H)$.

\begin{tabular}{|c|c|c|c|c|c|}
\hline \multirow{2}{*}{$\begin{array}{l}\text { Magnetostrictive } \\
\text { Powders }\end{array}$} & \multirow[t]{2}{*}{ Zn Ratio } & $\begin{array}{c}\text { Saturation } \\
\text { Magnetization }\end{array}$ & $\begin{array}{c}\text { Remanant } \\
\text { Magnetization }\end{array}$ & Coercive Field & $\begin{array}{c}\text { Magnetic } \\
\text { Susceptibility }\end{array}$ \\
\hline & & $M_{\mathrm{s}}(\mathrm{emu} / \mathrm{g})$ & $M_{\mathrm{r}}(\mathrm{emu} / \mathrm{g})$ & $H_{\mathrm{c}}(\mathrm{Oe})$ & $\underset{(\mathrm{emu} / \mathrm{g} \cdot \mathrm{Oe})}{\chi_{\max }}$ \\
\hline $\mathrm{CFO}$ & $\mathrm{Zn}=0$ & $74.5 \pm 0.75$ & $16.8 \pm 0.17$ & $366.2 \pm 3.66$ & 0.05 \\
\hline \multirow{2}{*}{$\mathrm{pCZFO}$} & $\mathrm{Zn}=0.1$ & $77.1 \pm 0.77$ & $18.5 \pm 0.19$ & $101.6 \pm 1.02$ & 0.22 \\
\hline & $\mathrm{Zn}=0.2$ & $75.9 \pm 0.76$ & $0.5 \pm 0.01$ & $2.4 \pm 0.02$ & 0.42 \\
\hline \multirow{2}{*}{$\mathrm{dCZFO}$} & $\mathrm{Zn}=0.1$ & $86.3 \pm 0.86$ & $9.3 \pm 0.09$ & $36.2 \pm 0.36$ & 0.34 \\
\hline & $\mathrm{Zn}=0.2$ & $82.6 \pm 0.83$ & $2.3 \pm 0.02$ & $10.8 \pm 0.11$ & 0.35 \\
\hline
\end{tabular}

To investigate structure-dependent $\mathrm{ME}$ responses, particulate $\mathrm{ME}$ composites were prepared with compositions of CFO-NKNLS, pCZFO-NKNLS $(\mathrm{Zn}=0.1,0.2)$, and dCZFO-NKNLS $(\mathrm{Zn}=0.1,0.2)$. From the XRD patterns, as shown in Figure 4, perovskite $\left(\mathrm{ABO}_{3}\right)$ and spinel $\left(\mathrm{AB}_{2} \mathrm{O}_{4}\right)$ crystal structures were confirmed as piezoelectric and magnetostrictive phases, respectively. Even though sintering was conducted at $1050^{\circ} \mathrm{C}$ for $2 \mathrm{~h}$, all ME composites were found to exhibit stable crystal structures without any trace of secondary phase. In particular, a peak split at $2 \theta=45-46^{\circ}$ representing a tetragonal phase 
was maintained during the high temperature sintering. Therefore, the ME composites were found to exhibit a piezoelectric charge constant $\left(d_{33}\right)$ of $55-60 \mathrm{pC} / \mathrm{N}$ after sample poling.

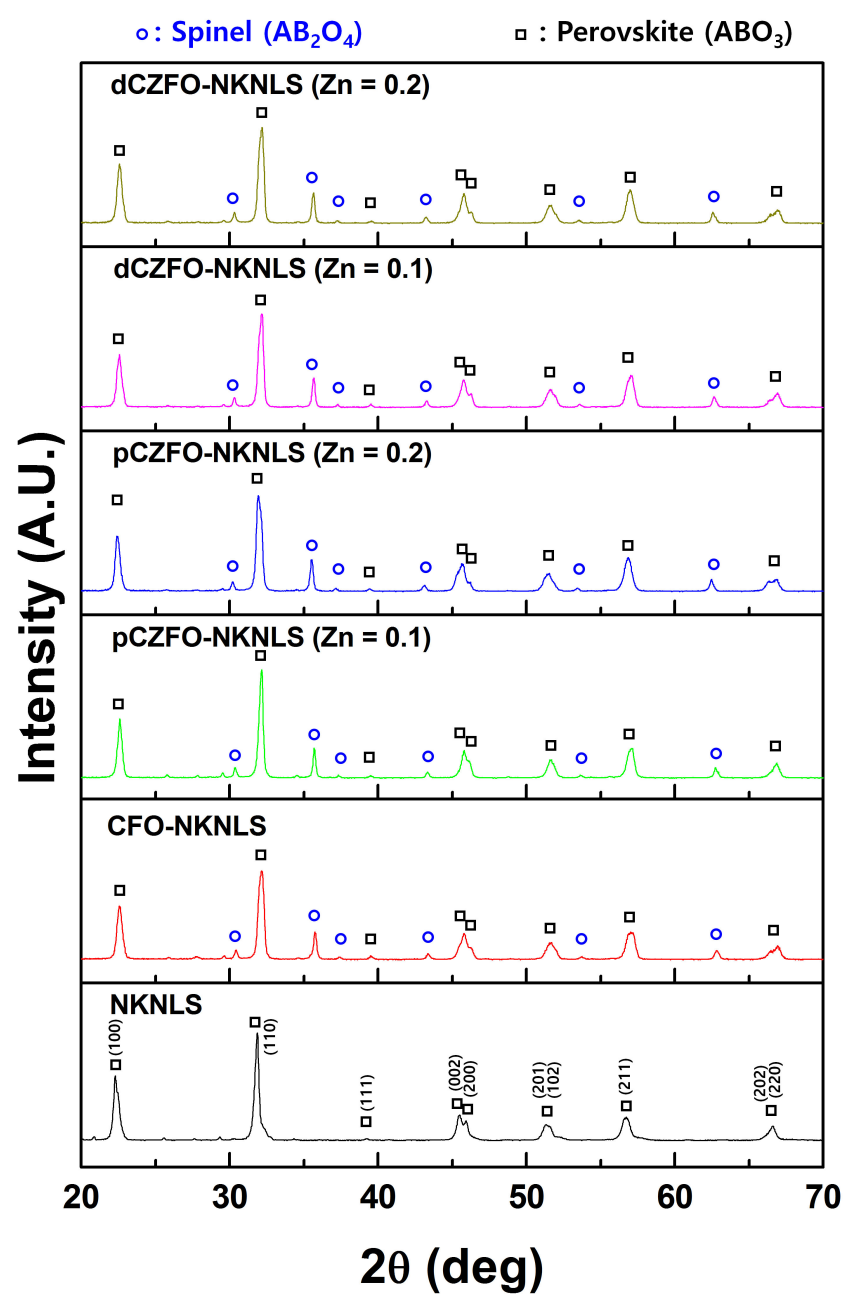

Figure 4. XRD patterns of magnetoelectric (ME) particulate composites consisting of a piezoelectric phase of NKNLS and magnetostrictive phases of CFO, pCZFO $(\mathrm{Zn}=0.1,0.2)$ and dCZFO $(\mathrm{Zn}=0.1,0.2)$.

From the particulate composites of CFO-NKNLS, pCZFO-NKNLS ( $\mathrm{Zn}=0.1,0.2)$, and dCZFO-NKNLS $(\mathrm{Zn}=0.1,0.2)$, ME voltage $\left(\alpha_{\mathrm{ME}}\right)$ and $H_{\mathrm{opt}}$. were investigated while applying $H_{\mathrm{ac}}=1 \mathrm{Oe}$ at $f=1 \mathrm{kHz}$ by sweeping $H_{\mathrm{dc}}$ of $\pm 1000 \mathrm{Oe}$, as shown in Figure 5 and Table 2. The CFO-NKNLS composites were found to exhibit a maximum $\alpha_{\mathrm{ME}}=140 \mu \mathrm{V} / \mathrm{cm} \cdot$ Oe at $H_{\text {opt. }}=966$ Oe. Even though a

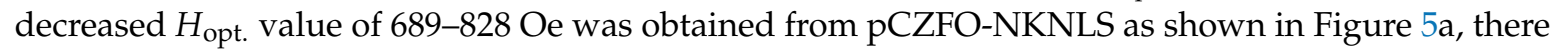
was not a sufficient $H_{\text {opt. }}$ shift due to its weak behavior of stepped demagnetization. On the other hand, the dCZFO-NKNLS composites were found to exhibit remarkable $H_{\text {opt. }}$ values of $458-481$ Oe as shown in Figure 5 b, which are lower $H_{\text {opt. values than any reported particulate ME composites }}$ so far. As a result, the structural effect of magnetostrictive powders on $H_{\text {opt. }}$ shift is clearly shown

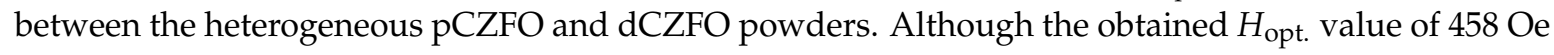
from dCZFO-NKNLS is higher than 100 Oe, this study can serve to minimize a required $H_{\text {opt. }}$ by complexation with previous studies for high feasibility of particulate ME composites. 

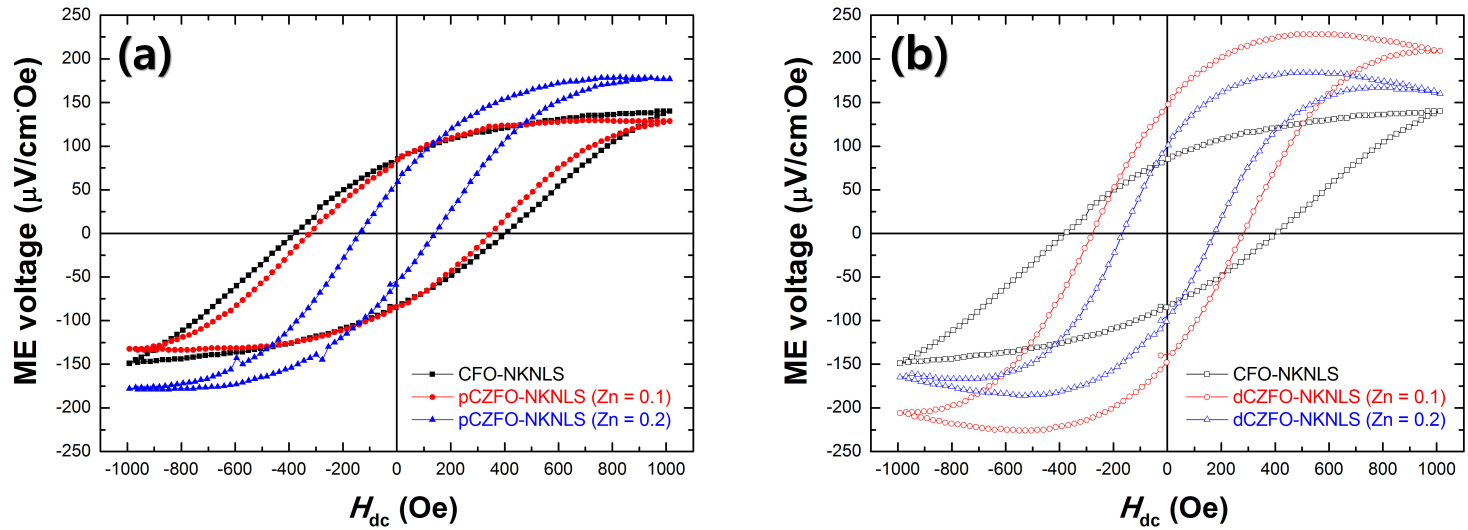

Figure 5. ME voltage of particulate composites consisting of a piezoelectric phase of NKNLS and magnetostrictive phases of (a) CFO and pCZFO $(\mathrm{Zn}=0.1,0.2)$ and $(\mathbf{b}) \mathrm{CFO}$ and dCZFO $(\mathrm{Zn}=0.1,0.2)$.

Table 2. Magnetoelectric (ME) responses of CFO-NKNLS, pCZFO-NKNLS, and dCZFO-NKNLS composites; optimal magnetic field $\left(H_{\mathrm{opt}}\right)$ and $\mathrm{ME}$ voltage $\left(\alpha_{\mathrm{ME}}\right)$.

\begin{tabular}{cccc}
\hline \multirow{2}{*}{$\begin{array}{c}\text { Magnetoelectric } \\
\text { Composites }\end{array}$} & Zn Ratio & Optimal Magnetic Field & Magnetoelectric Voltage \\
\cline { 2 - 4 } & & $\boldsymbol{H}_{\text {opt. }}(\mathbf{O e})$ & $\boldsymbol{\alpha}_{\mathbf{M E}}(\boldsymbol{\mu} \mathbf{V} / \mathbf{c m} \cdot \mathbf{O e})$ \\
\hline CFO-NKNLS & $\mathrm{Zn}=0$ & 966 & $140 \pm 21.0$ \\
\hline \multirow{2}{*}{ pCZFO-NKNLS } & $\mathrm{Zn}=0.1$ & 689 & $130 \pm 19.5$ \\
\cline { 2 - 4 } & $\mathrm{Zn}=0.2$ & 828 & $179 \pm 26.9$ \\
\hline \multirow{2}{*}{ dCZFO-NKNLS } & $\mathrm{Zn}=0.1$ & 481 & $228 \pm 34.2$ \\
\cline { 2 - 4 } & $\mathrm{Zn}=0.2$ & 458 & $184 \pm 27.6$ \\
\hline
\end{tabular}

\section{Conclusions}

In this study, magnetostrictive powders of CFO, $\mathrm{pCZFO}(\mathrm{Zn}=0.1,0.2)$ and $\mathrm{dCZFO}(\mathrm{Zn}=0.1,0.2)$ were prepared to produce low values of $H_{\text {opt. }}$, which is required to obtain a reliable ME voltage in a 3-0 type particulate composite system. Compared to the CFO powders $\left(\chi_{\max }=0.05 \mathrm{emu} / \mathrm{g} \cdot\right.$ Oe at $H_{\mathrm{dc}}$ below $\pm 200 \mathrm{Oe}$ ), the pCZFO and dCZFO powders were found to exhibit higher $\chi_{\max }$ of $0.22-0.42 \mathrm{emu} / \mathrm{g} \cdot \mathrm{Oe}$ at lower $H_{\mathrm{dc}}$ values below \pm 50 Oe and \pm 10 Oe, respectively. The NKNLS-based ME composites consisting of CFO, pCZFO, dCZFO, respectively were found to exhibit $H_{\text {opt. }}=966$ Oe (NKNLS-CFO), $H_{\text {opt. }}=689-828$ Oe (NKNLS-pCZFO), and $H_{\text {opt. }}=458-481$ Oe (NKNLS-dCZFO). The results illustrate

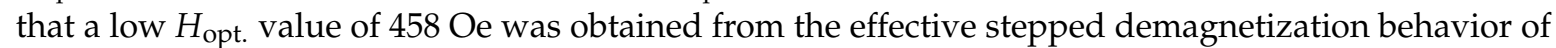
$\mathrm{dCZFO}(\mathrm{Zn}=0.2)$, which was induced by a structural effect in a heterogeneous magnetostrictive phase.

Author Contributions: Conceptualization, M.H.C. and S.C.Y.; methodology, M.H.C. and S.C.Y.; validation, M.H.C., K.K. and S.C.Y.; formal analysis, M.H.C.; investigation, M.H.C. and K.K.; resources, S.C.Y.; data curation, M.H.C. and K.K.; writing—original draft preparation, M.H.C.; writing—review and editing, S.C.Y.; visualization, M.H.C. and S.C.Y.; supervision, S.C.Y.; project administration, S.C.Y.; funding acquisition, S.C.Y.

Funding: This research was financially supported by the Dong-A University research fund.

Conflicts of Interest: The authors declare no conflict of interest.

\section{References}

1. Cheng, Y.; Peng, B.; Hu, Z.; Zhou, Z.; Liu, M. Recent development and status of magnetoelectric materials and devices. Phys. Lett. A 2018, 382, 3018-3025. [CrossRef]

2. Palneedi, H.; Annapureddy, V.; Priya, S.; Ryu, J. Status and Perspectives of Multiferroic Magnetoelectric Composite Materials and Applications. Actuators 2016, 5, 9. [CrossRef]

3. Ren, Y.; Ouyang, J.; Wang, W.; Wu, X.; Yang, X.; Zhang, Y.; Chen, S. Rotating Magnetoelectric Sensor for DC Magnetic Field Measurement. IEEE Trans. Magn. 2018, 54, 6001203. 
4. Yang, S.-C.; Ahn, C.-W.; Cho, K.-H.; Priya, S. Self-Bias Response of Lead-Free $(1-x)[0.948$ $\left.\mathrm{K}_{0.5} \mathrm{Na}_{0.5} \mathrm{NbO}_{3}-0.052 \mathrm{LiSbO}_{3}\right]-x \mathrm{Ni}_{0.8} \mathrm{Zn}_{0.2} \mathrm{Fe}_{2} \mathrm{O}_{4}$-Nickel Magnetoelectric Laminate Composites. J. Am. Ceram. Soc. 2011, 94, 3889-3899. [CrossRef]

5. Eerenstein, W.; Mathur, N.D.; Scott, J.F. Multiferroic and magnetoelectric materials. Nature 2006, 442, 759-765. [CrossRef] [PubMed]

6. Wang, Y.; Li, J.; Viehland, D. Magnetoelectrics for magnetic sensor applications: Status, challenges and perspectives. Mater. Today 2014, 17, 269-275. [CrossRef]

7. Fiebig, M. Revival of the magnetoelectric effect. J. Phys. D-Appl. Phys. 2005, 38, R123-R152. [CrossRef]

8. Nan, C.W.; Bichurin, M.I.; Dong, S.X.; Viehland, D.; Srinivasan, G. Multiferroic magnetoelectric composites: Historical perspective, status, and future directions. J. Appl. Phys. 2008, 103, 1. [CrossRef]

9. Li, T.; Ma, D.; Li, K.; Hu, Z. Self-biased magnetoelectric coupling effect in the layered $\mathrm{La}_{0.7} \mathrm{Sr}_{0.3} \mathrm{MnO}_{3} / \mathrm{BaTiO}_{3} / \mathrm{La}_{0.7} \mathrm{Sr}_{0.3} \mathrm{MnO}_{3}$ multiferroic heterostructure. J. Alloy. Compd. 2018, 747, 558-562. [CrossRef]

10. An, F.; Zhong, G.; Zhu, Q.; Huang, Y.; Yang, Y.; Xie, S. Synthesis and mechanical properties characterization of multiferroic $\mathrm{BiFeO}_{3}-\mathrm{CoFe}_{2} \mathrm{O}_{4}$ composite nanofibers. Ceram. Int. 2018, 44, 11617-11621. [CrossRef]

11. Islam, R.A.; Priya, S. Effect of piezoelectric grain size on magnetoelectric coefficient of $\mathrm{Pb}\left(\mathrm{Zr}_{0.52} \mathrm{Ti}_{0.48}\right) \mathrm{O}_{3}-\mathrm{Ni}_{0.8} \mathrm{Zn}_{0.2} \mathrm{Fe}_{2} \mathrm{O}_{4}$ particulate composites. J. Mater. Sci. 2008, 43, 3560-3568. [CrossRef]

12. Gupta, A.; Chatterjee, R. Dielectric and magnetoelectric properties of $\mathrm{BaTiO}_{3}-\mathrm{Co}_{0.6} \mathrm{Zn}_{0.4} \mathrm{Fe}_{1.7} \mathrm{Mn}_{0.3} \mathrm{O}_{4}$ composite. J. Eur. Ceram. Soc. 2013, 33, 1017-1022. [CrossRef]

13. Nie, J.W.; Xu, G.Y.; Yang, Y.; Cheng, C.W. Strong magnetoelectric coupling in $\mathrm{CoFe}_{2} \mathrm{O}_{4}-\mathrm{BaTiO}_{3}$ composites prepared by molten-salt synthesis method. Mater. Chem. Phys. 2009, 115, 400-403. [CrossRef]

14. Negi, N.S.; Kumar, R.; Sharma, H.; Shah, J.; Kotnala, R.K. Structural, multiferroic, dielectric and magnetoelectric properties of (1-x) $\mathrm{Ba}_{0.85} \mathrm{Ca}_{0.15} \mathrm{Ti}_{0.90} \mathrm{Zr}_{0.10} \mathrm{O}_{3}-(\mathrm{x}) \mathrm{CoFe}_{2} \mathrm{O}_{4}$ lead-free composites. J. Magn. Magn. Mater. 2018, 456, 292-299. [CrossRef]

15. Walther, T.; Straube, U.; Koferstein, R.; Ebbinghaus, S.G. Hysteretic magnetoelectric behavior of $\mathrm{CoFe}_{2} \mathrm{O}_{4}-\mathrm{BaTiO}_{3}$ composites prepared by reductive sintering and reoxidation. J. Mater. Chem. C 2016, 4, 4792-4799. [CrossRef]

16. Sreenivasulu, G.; Babu, V.H.; Markandeyulu, G.; Murty, B.S. Magnetoelectric effect of (100-x) $\mathrm{BaTiO}_{3}-(\mathrm{x}) \mathrm{NiFe}_{1.98} \mathrm{O}_{4}(\mathrm{x}=20-80 \mathrm{wt} \%)$ particulate nanocomposites. Appl. Phys. Lett. 2009, 94, 112902. [CrossRef]

17. Ryu, J.; Carazo, A.V.; Uchino, K.; Kim, H.E. Piezoelectric and magnetoelectric properties of Lead Zirconate Titanate/Ni-Ferrite particulate composites. J. Electroceram. 2001, 7, 17-24. [CrossRef]

18. Islam, R.A.; Viehland, D.; Priya, S. Doping effect on magnetoelectric coefficient of $\mathrm{Pb}\left(\mathrm{Zr}_{052} \mathrm{Ti}_{0.48}\right) \mathrm{O}_{3}-\mathrm{Ni}_{(1-x)} \mathrm{Zn}_{x} \mathrm{Fe}_{2} \mathrm{O}_{4}$ particulate. J. Mater. Sci. 2008, 43, 1497-1500. [CrossRef]

19. Yang, S.-C.; Kumar, A.; Petkov, V.; Priya, S. Room-temperature magnetoelectric coupling in single-phase $\mathrm{BaTiO}_{3}-\mathrm{BiFeO}_{3}$ system. J. Appl. Phys. 2013, 113, 144101. [CrossRef]

20. Shovon, O.G.; Rahaman, M.D.; Tahsin, S.; Hossain, A.K.M.A. Synthesis and characterization of (100-x) $\mathrm{Ba}_{0.82} \mathrm{Sr}_{0.03} \mathrm{Ca}_{0.15} \mathrm{Zr}_{0.10} \mathrm{Ti}_{0.90} \mathrm{O}_{3}+(\mathrm{x}) \mathrm{Mg}_{0.25} \mathrm{Cu}_{0.25} \mathrm{Zn}_{0.5} \mathrm{Mn}_{0.05} \mathrm{Fe}_{1.95} \mathrm{O}_{4}$ composites with improved magnetoelectric voltage coefficient. J. Alloy. Compd. 2018, 735, 291-311. [CrossRef]

21. Allaedini, G.; Tasirin, S.M.; Aminayi, P. Magnetic properties of cobalt ferrite synthesized by hydrothermal method. Int. Nano Lett. 2015, 5, 183-186. [CrossRef]

22. Ben Ali, M.; El Maalam, K.; El Moussaoui, H.; Mounkachi, O.; Hamedoun, M.; Masrour, R.; Hlil, E.K.; Benyoussef, A. Effect of zinc concentration on the structural and magnetic properties of mixed Co-Zn ferrites nanoparticles synthesized by sol/gel method. J. Magn. Magn. Mater. 2016, 398, 20-25. [CrossRef]

23. Ansari, S.M.; Sinha, B.B.; Pai, K.R.; Bhat, S.K.; Ma, Y.-R.; Sen, D.; Kolekar, Y.D.; Ramana, C.V. Controlled surface/interface structure and spin enabled superior properties and biocompatibility of cobalt ferrite nanoparticles. Appl. Surf. Sci. 2018, 459, 788-801. [CrossRef]

24. Köseoğlu, Y.; Baykal, A.; Gözüak, F.; Kavas, H. Structural and magnetic properties of $\mathrm{Co}_{x} \mathrm{Zn}_{1-x} \mathrm{Fe}_{2} \mathrm{O}_{4}$ nanocrystals synthesized by microwave method. Polyhedron 2009, 28, 2887-2892. [CrossRef]

25. Vaidyanathan, G.; Sendhilnathan, S. Characterization of $\mathrm{Co} 1-\mathrm{xZnxFe}_{2} \mathrm{O}_{4}$ nanoparticles synthesized by co-precipitation method. Phys. B 2008, 403, 2157-2167. [CrossRef]

26. Anjum, S.; Khurram, R.; Bashir, F.; Nazli, H. Fabrication and Investigation of Structural, Magnetic and Dielectrical Properties of Zn Substituted Co-ferrites. Mater. Today Proc. 2015, 2, 5515-5521. [CrossRef] 
27. Praveena, K.; Sadhana, K.; Liu, H.-L.; Murthy, S.R. Effect of Zn substitution on structural, dielectric and magnetic properties of nanocrystalline $\mathrm{Co}_{1-x} \mathrm{Zn}_{x} \mathrm{Fe}_{2} \mathrm{O}_{4}$ for potential high density recording media. J. Mater. Sci.-Mater. Electron. 2016, 27, 12680-12690. [CrossRef]

28. Bill, A.; Braun, H.B. Magnetic properties of exchange springs. J. Magn. Magn. Mater. 2004, 272-276, $1266-1267$. [CrossRef]

29. Chithra, M.; Anumol, C.N.; Sahu, B.; Sahoo, S.C. Exchange spring like magnetic behavior in cobalt ferrite nanoparticles. J. Magn. Magn. Mater. 2016, 401, 1-8. [CrossRef]

30. Lavorato, G.; Winkler, E.; Rivas-Murias, B.; Rivadulla, F. Thickness dependence of exchange coupling in epitaxial $\mathrm{Fe}_{3} \mathrm{O}_{4} / \mathrm{CoFe}_{2} \mathrm{O}_{4}$ soft/ard magnetic bilayers. Phys. Rev. B 2016, 94, 054405. [CrossRef]

2019 by the authors. Licensee MDPI, Basel, Switzerland. This article is an open access article distributed under the terms and conditions of the Creative Commons Attribution (CC BY) license (http://creativecommons.org/licenses/by/4.0/). 